\title{
Sinta o drama
}

de Iná Camargo Costa

Petrópolis, Editora Vozes, 1998

\section{Maria Sílvia Betti}

\section{Ecos da polêmica}

coletânea de ensaios intitulada Sinta o dra$m a$, de Iná Camargo Costa, reunindo textos sobre teatro e dramaturgia, veio a público antes que se esgotasse a polêmica suscitada pelo trabalho anterior da autora, A hora do teatro épico no Brasil, tese de doutorado publicada em 1996. Analisando as formas épicas pioneiras no teatro brasileiro, Iná punha ali em discussão a postura da crítica brasileira em geral, e de Décio de Almeida Prado e Sábato Magaldi em particular, diante do épico em seu momento de implantação no país.

A constatação do que seria uma atitude de resistência dos críticos diante do teor político do épico causou impacto e produziu acalorados debates, motivando matérias na imprensa e até alguma agitação na universidade, assim como artigos de Décio e Sábato. Se todo esse processo por um lado contribuiu para momentaneamente aumentar a repercussão do livro, acabou levando, por outro, a uma injusta dispersão das atençōes sobre as importantes análises das realizaçôes inaugurais do épico no Brasil elaboradas por Iná.
Tanto A hora do teatro épico no Brasil como Sinta o drama, lançado em outubro de 1998, são frutos de um projeto de base: o de análise dialética das relações entre o teatro e seus papéis dentro do contexto histórico e político do país. Em termos comparativos seria possível dizer-se que Sinta o drama contribui consideravelmente para explicitar a concatenação teóri$\mathrm{ca}$, crítica e histórica que fundamenta as investigações desenvolvidas em $A$ hora do teatro épico no Brasil.

Em sua natureza menos formal, o gênero ensaístico de Sinta o drama apresenta Iná no aspecto que ela, excelente comunicadora que é, parece efetivamente preferir: o da expressão menos distante da oralidade, que lhe permite manejar a ironia e, por vezes o humor, presente desde o jogo de sentidos contido no título.

Resultado da compilação de ensaios escritos entre 1990 e 1997, Sinta o drama aborda questôes cruciais para a compreensão da atividade teatral em um país periférico como o Brasil: tomando um ponto de vista independente por definição, Iná começa pela análise dos trabalhos de história e crítica do teatro que apresentam as características do drama burguês como

Maria Sílvia Betti é professora da FFLCH/USP; autora de Oduvaldo Vianna Filho (São Paulo, Edusp/ FAPESP, 1997); tradutora de O Método Brecht, de Fredric Jameson (Petrópolis, Ed. Vozes, 1999). 
"naturais" e "essenciais", e abstraem sua natureza histórica e politicamente determinada.

Apoiada nesse questionamento inicial, ela problematiza as etapas de construção do teatro moderno no Brasil, realizando uma visão ampla da produção dramatúrgica desde o século XIX, com Martins Pena e França Júnior, até o teatro das décadas de 1960 e 1970.

Com o respaldo teórico dos trabalhos de Roberto Schwarz ${ }^{1}$ e Peter Szondi (1962), Iná estabelece um diálogo crítico com Gyorgy Lukács e Theodor Adorno no plano internacional, e com Décio de Almeida Prado e Sábato Magaldi no nacional, retomando a questão do papel da crítica quanto à recepção do épico no Brasil.

A formação em Filosofia assegura-lhe uma grande familiaridade com o trabalho de pensadores como Kant, Hegel e Benjamin; a leitura atenta dos escritos teóricos de Brecht, por outro lado, fornece-lhe o instrumento para desenvolver o eixo principal de seu livro - a rediscussão histórica, política e teórica da crise do dramático e da construção do épico, com todos os seus avanços e recuos, e sua recepção por parte da crítica, nacional e internacionalmente.

O livro compóe-se de doze ensaios direcionados a algumas questóes centrais: a construção tardia da modernidade no teatro brasileiro, os problemas que envolvem a atividade teatral em um país de periferia como o Brasil, a discussão do trabalho de Décio de Almeida Prado, expoente maior da crítica no Brasil, o apanhado histórico-crítico da dramaturgia brasileira partindo de Martins Pena e França Júnior, e o esboço de uma visão de conjunto do teatro brasileiro nos anos 60 e 70 .

\section{Do dramático ao épico}

Tomando como prioridade a discussão da dramaturgia sem ignorar os aspectos cênicos e as relações de produção, Iná discute, inicialmente, o processo histórico que leva à crise do drama burguês enquanto forma, e à incorporação de recursos líricos e épicos, dentro do contexto da ascensão dos movimentos de massas da segunda metade do século XIX.

Sua preocupação é não apenas a de contextualizar o épico em sua gênese, mas também a de acompanhar os acidentes de percurso por ele sofridos desde então: a derrota da organização revolucionária do proletariado, o rápido esvaziamento das formas para as quais essa organização vinha se encaminhando, e a conseqüente retomada de algumas características da transição do drama moderno, do naturalismo ao expressionismo.

A referência a um recuo ao dramático motivada pelo esvaziamento dos movimentos operários em países como a Rússia, a Alemanha e os Estados Unidos - requer atenção para que não se atribua injustamente à análise de Iná uma conotação qualitativa e maniqueísta, de descarte puro e simples da forma dramática.

A questão por ela implícita não é a de proscrever o drama, e sim a de conferir o devido relevo histórico ao processo em que este passa a conviver com outras formas de expressão, as quais apontam, cada vez mais, para a necessidade de registrar experiências não mais figuráveis nos termos da expressão de um conflito envolvendo uma individualidade protagonista.

A propósito desta questão, Iná oferece ao leitor um interessante panorama da história das formas teatrais ao apontar, por exemplo, que também nos contextos russo e norte-americano verifica-se um retrocesso do épico no teatro: no caso russo isso se dá com a abolição da experimentação livre pela facção stalinista vitoriosa;

1 Particularmente “Idéias fora do Lugar” (1977) e “Cultura e Política: 1964-1969” (1978). 
no norte-americano, dá-se com a inversão do sentido original da experiência épica com o Living Newspaper ${ }^{2}$ nos anos 30, quando o controle é delegado à esfera estatal do governo Roosevelt. Iná também discute o caso da França, observando que a apropriação do épico por Claudel, por exemplo, efetuou-se apenas no plano do arcabouço expressivo, e não no do conteúdo propriamente dito.

O percurso de Bertolt Brecht é apresentado, dentro dessa perspectiva, a partir dos matizes políticos de suas diferentes fases: o Pequeno organon, por exemplo, escrito em 1948, quando da volta do autor à Alemanha após seu longo exílio, revela, por parte do autor, uma forma de aclimatação de suas próprias teorias às novas condições, uma vez que recupera a noção dramática de ação, e "capitula", assim, politicamente, em relação às formulações de vinte ou trinta anos antes.

\section{Resistência e rendição}

Ao voltar-se à discussão do teatro no Brasil, Iná apóia seu raciocínio de base no conceito de idéias fora do lugar tomado a Roberto Schwarz. Seu objetivo é, em essência, o de evidenciar aquilo que denomina o nosso "torcicolo cultural”, motivado pela defasagem entre o ritmo lento das relações sociais de produção e o ritmo rápido das modificações ideológicas das elites, às quais o processo cultural das metrópoles está atrelado.
Para a autora, nossos processos de atualização cultural operam sempre através de "filtros", que atuam em consonância com a perspectiva das classes hegemônicas, tanto no sentido de eleger modelos quanto no de omitir aspectos que destoem de sua perspectiva.

Assim, os próprios processos de renovação dramatúrgica, com a tomada de Tennessee Williams e Arthur Miller como modelos, não teriam surgido gratuitamente dentro de um contexto como o brasileiro, onde a política de substituição de importações criara condições de produção ilusoriamente assemelhadas às da Europa e dos Estados Unidos.

Para Iná o marco de renovação teatral na dramaturgia brasileira encontra-se na montagem de $A$ moratória, de Jorge Andrade, pelo Teatro Maria della Costa, em 1955. Nessa fase, a absorção da modernidade implantada pelo TBC já havia se processado, e as pressões sociais decorrentes das reivindicações das classes trabalhadoras haviam aberto caminho para encenaçôes de autores comprometidos com as lutas políticas da esquerda.

Duas alas opostas são apontadas por ela dentro do setor teatral nesse momento: uma, representada por Sábato Magaldi e José Renato, que preconizam o patrocínio estatal com base na experiência de Jean Vilar ${ }^{3}$ na França, e outra, mais radical, encabeçada por Vianinha e ligada à atuação do $\mathrm{CPC}$ da $\mathrm{UNE}^{4}$ e ao $\mathrm{MCP}^{5}$ de Pernambuco. Ambas as vertentes sofrem, após 1964, os efeitos da ruptura imposta pelo

2 Setor do Federal Theater Project (projeto estatal para a cultura e as artes em vigor entre os anos de 1933 e 1939) integrando o conjunto de políticas administrativas de reerguimento econômico conhecidas como New Deal, durante o governo Roosevelt nos Estados Unidos.

3 Dramaturgo, encenador e fundador do Festival de Avignon em 1947. Discípulo de Dullin, iniciou sua carreira de diretor durante a Ocupação. Em 1951 torna-se diretor do Théatre National Populaire, defendendo a idéia de que o teatro devia ser um serviço público disponível a todos.

4 Centro Popular de Cultura da União Nacional dos Estudantes, fundando a partir de mobilização dos setores intelectuais de esquerda desencadeada pela encenação de A Mais Valia vai acabar, seu Edgar, de Oduvaldo Vianna Filho, no Rio de Janeiro em 1960/61.

5 Movimento de Cultura Popular: projeto de educação e cultura integrante das medidas implantadas pelo governo Miguel Arraes, de Pernambuco no início dos anos 60. 
golpe militar e pela subseqüente hegemonia, dentro da esquerda, do que Iná denomina a "opção pessedista", apoiada na idéia da aliança de classes como base para a resistência democrática.

Dentro do panorama traçado deste período, Iná toca novamente na questão da postura da crítica, renitente, em seu entender, em não admitir o teor ideológico implícito no trabalho de Bertolt Brecht. Esse dado indicaria, em si só, que não é absolutamente casual o fato de o conceito de "dramático" haver se tornado hegemônico a ponto de ser tomado como equivalente de "teatral".

Alertando sempre para o fato de que o épico tem inimigos, Iná revisita a questão desencadeadora dos debates a propósito de $A$ hora do teatro épico no Brasil, ou seja, discute a postura da grande crítica diante do épico em sua fase inaugural: seu intuito é não o de voltar à polêmica, mas o de discutir em profundidade o processo de recepção do épico a partir da montagem de $A$ alma boa de Se-Tsuan. O foco de interesse a este respeito é novamente a crítica de Décio de Almeida Prado, a quem ela se refere reverentemente como "mestre" e em cujo trabalho aponta uma dívida "que o tempo não esmorece", segundo suas próprias palavras.

O reconhecimento do mérito do trabalho brechtiano por parte de Décio só ocorre, segundo Iná, a partir de 1967, momento em que ele passa a destacar positivamente, ainda que de forma velada, o rigor da forma no trabalho do dramaturgo alemão. Para a autora, o caráter velado desse "render-se a Brecht" de Décio teria duas possíveis explicações: o conserva- dorismo do jornal O Estado de S. Paulo, onde o crítico atuava, ou a autocensura resultante de uma postura pessoal de anticomunismo.

\section{Ressalva Metodológica}

É de se observar, a respeito do tratamento dispensado por Décio ao épico, que Iná não questiona o teor das encenações brechtianas que serviram de base para as críticas por ele elaboradas, embora ressalte a "confissão" de Décio de que o épico parecera-lhe mais atraente como texto do que como encenação. Seria o caso de se examinar se as encenaçôes discutidas pelo crítico teriam sido razoavelmente consistentes no tratamento cênico das concepções épicas, e se teriam efetivamente trabalhado a dimensão política inerente ao trabalho de Brecht.

Iná ainda não estendeu, até o momento, seu campo de observação para a produção de outros críticos contemporâneos a Décio (ainda que apenas referencialmente, com o sentido de aferir seus próprios padrões de avaliação). Patrícia Galvão, por exemplo, insuspeitadamente consciente da dimensão política intrínseca à arte (ainda que, nessa fase, já não mais a preconizasse como premissa de trabalho), não concede grande ênfase ao papel da reflexão política em A alma boa de Se-Tsuan, e até, pelo contrário, relativiza-a ${ }^{6}$.

A impressão que se tem a esse respeito e que figura aqui apenas à guisa de apontamento para investigações futuras - é que a própria esquerda não respondeu com formulações muito diversas das de Décio naquele momento específico de aporte das concepções de Bertolt Brecht.

6 Apenas à guisa de ilustração veja-se o comentário de Patrícia Galvão a propósito da montagem de $A$ alma boa de Se-Tsuan em sua coluna Palcos \& Atores, publicada semanalmente no suplemento dominical de A Tribuna de Santos entre 1957 e 1961: “O extraordinário mérito da obra de Brecht - é preciso alardear bem - está em que a intenção clara de proselitismo político, a qual em outras circunstâncias amesquinharia o resultado artistico, aqui não atua negativamente e até se deixa apagar pela beleza literária" (Crônica intitulada Brecht invade o Brasil. Jornal A Tribuna de Santos, Suplemento Dominical no 75, p. 7, coluna "Palcos \& Atores", 31/08/1958). 
O movimento mais agudo de reflexões só ganharia impulso, efetivamente, com o grupo do Arena, com Boal, Vianinha e Chico de Assis, para os quais o trabalho brechtiano seria o desencadeador de profundas transformações.

É necessário investigar-se mais de perto as condições em que se verifica este processo de introdução do épico no Brasil - particularmente no campo da produção crítica da esquerda. Sem dúvida alguma trata-se de uma empreitada considerável, demandando um esforço documental de grande porte. A agudeza do pensamento crítico de Iná merece, porém, que ela venha a fazê-lo a fim de não se deixar relativizar por este "senão" metodológico.

\section{Matrizes da crítica}

Voltando à natureza do pensamento teatral de Décio, Iná discute as matrizes de sua formação teórica, situadas nas formulações de Jacques Copeau e de Louis Jouvet - ambos preconizadores do respeito ao texto - e no teatro de Paul Claudel, outro autor que merece grande destaque nas formulaçôes do crítico.

Também Giradoux e Pirandello desempenham, no entender de Iná, papel relevante no processo de formação do pensamento teatral de Décio: o primeiro enquanto modelo a ser atingido, e o segundo por seu pioneirismo e profundidade, qualidades consideradas por ele ausentes no trabalho brechtiano.

Os termos da rendição de Décio a Brecht são, a esta altura, relativizados por Iná em função da reverência do crítico diante de Pirandello dentro da criação teatral no século XX. A adesão do dramaturgo italiano ao fascismo, ainda que temporária, leva a autora a problematizar a colocação de Pirandello como um humanista, e a considerar que a desvinculação do estético e do político tende a valer apenas quando se trata de desqualificar os comunistas.

A sondagem crítica do trabalho de Décio é complementada no ensaio em que Iná resenha Décio de Almeida Prado: um homem de teatro, coletânea de ensaios lançada em forma de livro-homenagem comemorando os oitenta anos do crítico, professor e historiador do teatro brasileiro (Aguiar et. al., 1998).

Dentre os estudos integrantes da edição Iná ressalta aqueles que enfocam aspectos da formação intelectual da geração de Décio, e que apontam as relações desta com o modernismo (Prado, 1998) e com o cinema (Fraga, 1998). Destaca, também, os ensaios que discutem dados específicos da constituição do pensamento do crítico, examinando, por exemplo, seu diálogo com os companheiros de geração da revista Clima (Faria, 1998), a importância das formulações de Stanislavski em seu pensamento teatral (Bernstein, 1998) e suas reflexões sobre a história do teatro no Brasil e sobre a autonomia da arte (Aguiar, 1998).

\section{Fio da meada}

Mais do que simples coletânea de trabalhos prépublicados, Sinta o drama evidencia, por parte de Iná, a presença marcante de um projeto crítico-interpretativo: sente-se, ao longo dos ensaios, a existência de um fio condutor que concatena as investigações - uma linha de procuras e de reflexôes que lhe permitem constituir um conjunto orgânico de leituras - uma interpretação no sentido pleno, que transcende a natureza circunstancial característica de coletâneas semelhantes.

Pode-se assim, a esta altura, apontar algumas linhas mestras que embasam a perspectiva crítica de Iná: antes de mais nada tem-se o estudo sistemático e detalhado do pensamento filosófico, crítico e historiográfico que fundamenta o drama burguês e, com o colapso deste, o surgimento do épico no teatro. Tem-se, paralelamente, o mergulho profundo nas leituras das teorias teatrais que respaldaram a construção da modernidade, de suas variantes, e das formas que resistiram a ela. Finalmente, no plano da discussão do teatro no contexto nacional, temse a leitura atenta das produções dramatúrgicas e críticas, com vistas a uma recolocação de balizas para o estudo do teatro brasileiro moderno. 


\section{Discutindo mal entendidos e equívocos}

Levantar e discutir mal entendidos vigentes na esfera teórica ou conceitual envolvida: esta é, nos ensaios de Iná, a estratégia freqüente que lhe permite caracterizar com objetividade o campo específico em que um determinado segmento de reflexões e análises irá se desenvolver. É o que ocorre, por exemplo, com a abordagem que faz de questões como a aproximação indevida, como ressalta a autora - entre a teatralidade de Meyerhold (que visa à aproximação com o espectador) e a de Brecht (que visa ao distanciamento crítico).

Outro significativo mal entendido analisado diz respeito à crítica que Alencar e Machado realizam do teatro de Martins Pena: a confusão conceitual vislumbrada aí se liga, segundo Iná, aos modelos dramatúrgicos então vigentes - Molière, Dumas e Beaumarchais. Nas décadas de 50 e 60 do século XIX a dramaturgia nacional via-se em pleno processo de luta pela implantação do drama burguês. Em conseqüência, o que tendia a predominar era uma atitude de descarte diante de formas que representam algum tipo de ruptura com as premissas que o respaldavam.

A ocorrência de equívocos conceituais não é, entretanto, apanágio do drama em seu processo de implantação no país: não escapam ao rigor crítico de Iná dados como a transformação do épico em artigo de consumo, verificável principalmente a partir do gradual abandono da experiência de autores como Boal e Guarnieri, que tratam Zumbi e Tiradentes ${ }^{7}$ como heróis, comprometendo assim pela base qualquer possibilidade de rendimento épico dos dois textos.

Para Iná, as chances do épico no país encerram-se com Tiradentes, em 1967, num momento em que, paralelamente, o Oficina arvorava-se em revolucionário e crítico das esquerdas enquanto José Celso tornava-se griffe com consciência plena desse processo.

$\mathrm{Na}$ raiz de todos os mal entendidos apontados, encontra-se sempre a recorrência do que Roberto Schwarz denomina "idéias fora do lugar”: as modificações culturais verificadas acompanham não o ritmo das relações de produção, mas o processo cultural das elites, que deshistoriciza seus modelos e descontextualiza as releituras deles - exemplos disso seriam William Saroyan encenado no TBC sem qualquer referência a seu esquerdismo, ou as apresentações de Ralé e $A$ exceção e a regra, em temporada simultânea no TBC e na EAD, sem qualquer menção, segundo Iná, ao seu significado político.

Do balanço que empreende do papel desempenhado pelos nomes exponenciais de nossa crítica teatral, há de se ressaltar a referência elogiosa feita ao trabalho de Gilda de Mello e Souza, "discreta madrinha do TBC", que não se submeteu aos modelos críticos da versão francesa do teatro moderno. É modelar, nos termos de Iná, a análise que Gilda realiza de $A$ Moratória, obra que considera fundante da modernidade no teatro brasileiro, e que a leva a saborosamente observar que "nunca haverá uma ensaísta como dona Gilda". Ressaltando a originalidade, a pertinência e a agudeza analítica do pensamento da autora, Iná subscreve com entusiasmo as reflexões da crítica e ensaísta, que pioneiramente situam a grande baliza de nossa modernização dramatúrgica no ano de 1955, com a montagem do texto de Jorge Andrade doze anos após a estréia de Vestido de noiva, de Nélson Rodrigues.

Para Iná tem-se aqui uma importante e preciosa diretriz de pesquisa para estudos futuros: a da investigação do fracasso das tentativas de se implantar entre nós o modelo dramático burguês em sua forma plena. $\mathrm{O}$ propalado "defeito" mais recorrentemente apontado em Martins Pena, por exemplo - o de inserir narra-

7 Arena conta Zumbi e Arena conta Tiradentes, de Augusto Boal e Gianfrancesco Guarnieri. 
ções interrompendo o fluxo da ação - poderia ser lido não como falha e sim como utilização de uma forma aproximada ao épico e não prevista pelos cânones dramáticos, sendo por isso, sumariamente condenada.

\section{Rumos de Pesquisa}

Apontar rumos de pesquisa para estudos futuros é outra das características recorrentes do trabalho de Iná. Inúmeros outros casos além do que acabamos de citar podem ser rastreados ao longo de Sinta o drama: a aproximação crítica das obras de Martins Pena e Manoel Antonio de Almeida (neste caso, especificamente, seguindo sugestão de Antonio Cândido), o resgate do teatro de opereta em seu processo de nacionalização, o tema do abandono da esfera agrícola e da adoção de uma vida pautada na especulação financeira, presente nas peças de França Júnior e o exame da história do drama sob a perspectiva feminina - estes são alguns exemplos de rumos apontados, indicando a preocupação de Iná com a ainda predominante exigüidade da produção histórico-crítica voltada ao teatro no Brasil.

Algumas vezes, os rumos sugeridos expressam-se não sob a forma de temas, mas de hipóteses de pesquisa: é o que ocorre quando ela observa, a propósito de Eles não usam blacktie, que o episódio inaugural de crise do teatro moderno no Brasil envolve uma revisão do papel feminino (referência ao enfrentamento crítico que as duas personagens femininas principais da peça fazem do protagonista Tião em seu intuito de furar a greve). É, também, o que ocorre quando afirma que, se em alguma vez houve um momento efetivo de revolução no teatro no Brasil, este se deu dentro do trabalho do CPC da UNE no início dos anos 60.

A densidade crítica do pensamento de Iná evidencia um conhecimento amplo e ao mesmo tempo profundo do repertório dramatúrgico e teórico, instigando o leitor a informar-se e a posicionar-se diante das abordagens. Sinta $o$ drama, assim como $A$ hora do teatro épico no Bra- sil, não poderá nunca ser lido com intuito meramente informativo ou então destituído de perspectiva histórica, e se em alguns momentos o envolvimento de Iná com seu objeto torna um tanto quanto inflexível o seu raciocínio, isso não lhe tira, potencialmente, o talento dialético para o debate.

\section{Sentindo o drama}

Todo o pensamento teórico desenvolvido em Sinta o drama está apoiado na observação do caráter social da forma, verdadeiro sismógrafo das tensões sociais, no dizer da autora. Com base em Raymond Williams o processo de superação das convenções artísticas vigentes nas diversas fases é investigado e discutido; por outro lado, o trabalho de Peter Szondi lhe permite acompanhar o processo de crise da forma dramática e de configuração do épico.

Recapitulando a fase de implantação do teatro moderno no Brasil, Iná observa que o país teria ficado à margem da revolução em processo nas artes cênicas entre 1887 e 1933, e que a própria França, pátria de nossos modelos culturais, ficara a reboque das renovações verificadas após o naturalismo, assumindo posição francamente regressiva.

O quadro aí esboçado complementa a contextualização do épico em seu momento de implantação no país. Mas não é apenas no âmbito nacional que Iná investiga e discute a recepção do épico: em "Brecht, Adorno e o interesse do engajamento", são colocadas em questão as restriçōes feitas por Theodor Adorno à dramaturgia brechtiana.

O fundamento crítico de Adorno é que, no tocante à necessidade do engajamento e da resistência, as obras devem agir exclusivamente através da forma. Segundo o pensador alemão, Samuel Beckett cumpre essa exigência, ao contrário de Brecht - e Santa Joana dos Matadouros e $A$ resistivel ascensão de Arturo Ui seriam exemplos concretos disso.

Tratando de discutir pormenorizadamente os argumentos de Adorno, Iná questiona a co- 
locação do crítico, que considera problemático o fato de Brecht em Santa Joana escolher tratar de episódios ligados à circulação de mercadorias e à disputa entre concorrentes, e não do processo de apropriação da mais-valia envolvendo a esfera da produção.

Para Iná a escolha de Brecht é estratégica por produzir imagens reveladoras das prioridades do capital e dos que o detêm. Dessa forma, não seriam as maquinações dos corretores, em Santa Joana, que são pueris, como afirma Adorno, mas sim a suposição feita por eles de que detêm o controle sobre a disputa em que se engalfinham.

As restrições feitas a Arturo Ui são, igualmente, alvo de contestações por Iná. Ao contrário do que afirma Adorno, Brecht estaria empenhado em mostrar não o horror do fascismo como mero acidente ou crime, mas sim a conivência da sociedade, que aposta na manutenção de relações pouco éticas de produção.

Também o rebaixamento da imagem da lei, ao contrário da opinião do crítico, representa, em seu entender, uma forma de mostrar a proximidade do inimigo, e não sua fragilidade. A abordagem do fascismo através do humor que tanto chocou Adorno - tem, para Iná, a função preconizada por Brecht de ridicularizar os grandes delitos políticos.

Embora observe que as posições rebatidas por Adorno não representam a postura final do autor, Iná critica, ainda, a tomada do teatro de Brecht como um teatro de didatismo político, enfatizando que as peças didáticas foram criadas basicamente para o treinamento de atores.

Os três últimos ensaios do livro, menos abrangentes em sua elaboração, oferecem interessante introdução a temas que se complementam no sentido de evocar um painel do teatro das últimas décadas do século XX: "Papéis de mulher no teatro brasileiro" mostra como os pilares do drama excluem as possibilidades de mulheres tornarem-se protagonistas; "Teatro e revolução nos anos 60" reivindica para a experiência estética do CPC um grau de realização situado além da mera agitação e palavras de ordem, e aponta para o caráter revolucionário presente também em seu processo de construção de imagens; "Um enredo para Flávio Império", que fecha o volume, destaca o empenho do cenógrafo em desenvolver uma concepção de espaço capaz de sensibilizar e estimular a reflexão crítica.

\section{Balanço Final}

Marco do ensaísmo teatral no Brasil, Sinta o drama é um livro generoso no sentido do estímulo que representa à reflexão e à pesquisa.

Apesar de sua forma de coletânea de ensaios, o caráter de tese se faz nele tão presente e funcional quanto em $A$ hora do teatro épico no Brasil, uma vez que Iná postula, ilustra e discute as hipóteses que têm orientado, desde o início, sua linha investigativa. Os fracassos no processo de implantação do drama no Brasil são apontados como fundamentais para que se compreenda o processo de construção de nosso teatro; paralelamente, a adoção do princípio do drama burguês por nossa intelectualidade é discutida a partir de alguns dos mais sérios condicionamentos a que deu origem e que se encontram ainda longe de serem superados.

O eixo central das formulações é sempre o estudo das condiçôes em que se dá a supressão do épico, após um certo período de manifestação, evidenciando a vigência de uma hierarquização das formas teatrais e uma estratégia de conciliação ideológica, típica de um contexto de capitalismo tardio como o brasileiro.

Contundente em seus diagnósticos, a análise de Iná não é nunca tópica ou centrada no alinhavar puro e simples de dados esparsos: há sempre a construção de uma base interpretativa, fundada na leitura e na análise da produção teatral ou crítica em questão.

Acompanhar o desenvolvimento das análises de Sinta o drama equivale a uma revisitação crítica de certas noções anteriormente sedimentadas sobre o passado histórico do teatro nacional.

Num momento político como o atual, em que nos vemos diante do sucateamento da 
cultura, da mercantilização da arte e da crescente dilapidação do espírito universitário digno desse nome, o livro de Iná é oportuno e instigante desde o apelo que nos faz em seu título. Se concordarmos que ante esse estado de coisas cabe ao teatro um fundamental papel na reflexão crítica e que esta é o primeiro e necessário passo para a práxis transformadora, Sinta o drama é certamente uma leitura imprescindível.

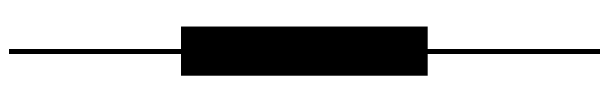

\section{Referências bibliográficas}

AGUIAR, AREAS \& FARIA (orgs.). Décio de Almeida Prado: um homem de teatro. São Paulo, EDUSP/ FAPESP, 1998.

COSTA, I.C. A hora do teatro épico no Brasil. Rio de Janeiro, Paz e Terra, 1996.

SCHWARZ, R. "Idéias fora do Lugar". In: Ao Vencedor as batatas. São Paulo, Duas Cidades, 1977. 1978.

“Cultura e política 1964-1969”. In: O pai de família e outros estudos. Rio de Janeiro, Paz e Terra,

SZONDI, P. Teoria del dramma moderno. Torino, Einaudi, 1962.

Artigos da coletânea Décio de Almeida Prado: um homem de teatro (AGUIAR et. al., 1998):

AGUIAR, F.W. "A Pura Chama: Estudo sobre Autor, Texto e Personagem na Obra de Décio de Almeida Prado".

BERNSTEIN, A. "A Arte do Crítico e a Arte do Ator".

FARIA, J.R. "Um tema: a formação do teatro brasileiro".

FRAGA, E. “Aprendizagem com Décio”.

PRADO, A.A. "O Teatro de Décio de Almeida Prado". 